\title{
A Comparative Evaluation of Efficacy of Streptococcus mutans Counts in Saliva: An in vivo Study
}

\author{
${ }^{1}$ Megha Sharma, ${ }^{2}$ Inder K Pandit, ${ }^{3}$ Nikhil Srivastava, ${ }^{4}$ Neeraj Gugnani, ${ }^{5}$ Monika Gupta
}

\begin{abstract}
Dental caries is a disease of multifactorial origin and Streptococcus mutans is considered as the chief pathogen responsible for its development. However, reduction in the number of pathogenic bacteria, particularly $S$. mutans, with the use of various preventive measures, can reduce dental caries to a significant level. Therefore, the present clinical study was undertaken to evaluate and compare the efficacy of toothbrushing, fluoride varnish, chlorhexidine mouthwash, and a probiotic (Yakult) in reducing the $S$. mutans counts in the saliva using Dentocult SM Strip Mutans kit in children. A total of 40 school students between the age group of 4 and 8 years were selected for the study and S. mutans count was taken on the first dental visit using Dentocult SM Strip Mutans test kit. After the initial scores of S. mutans were obtained, the children were divided into four groups and provided with different caries preventive regimen for 2 weeks. After 2 weeks, the scores of $S$. mutans were reevaluated for reduction in their counts, if any. The data thus collected were tabulated and statistically analyzed. All the groups showed a significant reduction in S. mutans counts with the highest reduction from the Fluor Protector varnish followed by chlorhexidine mouthwash, probiotic (Yakult), and toothbrushing.
\end{abstract}

Keywords: Chlorhexidine mouthwash, Dental caries, Fluor protector varnish, Probiotic (Yakult) and dentifrice, Streptococcus mutans.

How to cite this article: Sharma M, Pandit IK, Srivastava N, Gugnani N, Gupta M. A Comparative Evaluation of Efficacy of Streptococcus mutans Counts in Saliva: An in vivo Study. Int J Clin Pediatr Dent 2018;11(2):94-99.

Source of support: Nil

Conflict of interest: None

\section{INTRODUCTION}

Dental caries is a complex disease that is expressed as an interaction of various factors including the host, agent,

${ }^{1}$ Senior Resident, ${ }^{2,3}$ Principal, Professor and Head, ${ }^{4,5}$ Professor

${ }^{1}$ Department of Dental Surgery, Vardhman Mahavir Medical College \& Safdarjung Hospital, New Delhi, India

$2,4,5$ Department of Pedodontics and Preventive Dentistry, D.A.V. (C) Dental College \& Hospital, Yamunanagar, Haryana, India

${ }^{3}$ Department of Pedodontics and Preventive Dentistry, Subharti Dental College, Meerut, Uttar Pradesh, India

Corresponding Author: Megha Sharma, Senior Resident Department of Dental Surgery, Vardhman Mahavir Medical College \& Safdarjung Hospital, New Delhi, India, Phone: +919899768828, e-mail: megha.sharrma@gmail.com substrate, and time. ${ }^{1}$ This concept of interplay of these factors is widely accepted and is aptly described by WD Miller's chemicoparasitic theory, which postulates that the initial demineralization of tooth enamel is brought about by acids produced by bacteria present on the tooth.

From the day there has been pain associated with caries, scientists from all over have been finding ways not only to cure the already established lesion, but also to prevent it at an early age. The various caries preventive measures have been broadly classified into mechanical, chemical, and dietary control measures. Among the mechanical means, toothbrushing is the most common devise used for oral hygiene maintenance. ${ }^{2}$ Also, the bisbiguanide chlorhexidine, which has been studied extensively for over 20 years, is currently the most potent chemotherapeutic agent against mutans streptococci and dental caries. ${ }^{3}$

Furthermore, fluoride has been found to be the most effective cariostatic agent in the field of dentistry, especially in pediatric dentistry. ${ }^{4}$ There are various modes of fluoride application, and, among them, fluoride varnishes are known to cause most significant reduction in S. mutans counts, are recommended for use in preschool children, and seem to be the most suitable and documented regimen for the infants.

Prevention has gone one step ahead with a rapidly expanding arena of probiotics. They are live microbial food or feed supplements, which beneficially affect the host by improving its intestinal microbial balance and therefore, its nutritional health and well-being. Yakult, a probiotic has been commonly used for the gut, which contains Lactobacillus casei Shirota strain. A study by Hor et $\mathrm{al}^{5}$ showed that Yakult is a promising innovative therapy for caries prevention among children.

Various parameters have been used in the past to evaluate the efficacy of preventive measures. Microbial monitoring has been considered as an effective method for evaluating current caries activity and future caries risk. ${ }^{4}$ Reduction in the number of pathogenic bacteria, particularly S. mutans, can reduce dental caries to a significant level with the use of various preventive measures.

The application of microbial tests to assess caries risk in children was demonstrated initially by Krasse. ${ }^{6}$ In the first epidemiological surveys, tongue blades and agar plates were used, but these proved impractical for 
fieldwork and were replaced with liquid media into which the saliva-contaminated strips were inserted. ${ }^{7}$ These chair-side caries activity tests have been thoroughly compared with conventional selective agar plate culture. The comparison yields a good correlation with regard to detection of mutans streptococci. ${ }^{8}$

The Dentocult SM Strip Mutans test kit, introduced by Jensen and Bratthall, ${ }^{9}$ is a reliable method for measuring the status of dental caries in preschool children and also a valuable tool in the prevention and treatment of dental caries according to Shi et al. ${ }^{10}$ This is a chair-side caries activity test ensuring greater patient compliance, especially for young subjects, is less time consuming, needs minimum armamentarium, and facilitates sample selection.

The present clinical study was undertaken to evaluate and compare the efficacy of toothbrushing, fluoride varnish, chlorhexidine mouthwash, and a probiotic (Yakult) in reducing the $S$. mutans counts in the saliva using Dentocult SM Strip Mutans test kit in children.

\section{MATERIALS AND METHODS}

The present study was conducted in the outpatient Department of Pedodontics and Preventive Dentistry, D.A.V. (C) Dental College \& Hospital, Yamuna Nagar, Haryana, India, to evaluate and compare the efficacy of various caries preventive measures in reducing $S$. mutans counts in saliva using Dentocult SM Strip Mutans test kit.

An ethical committee approval was taken from the college authorities for conducting the study which was followed by a written consent from the parents of the school students selected as subjects regarding the commencement of the procedure.

A total of 40 school students between the age group of 4 and 8 years, having a decayed, missing and filled teeth score $\geq 5$ were selected from various schools of Yamuna Nagar.

Streptococcus mutans count was taken for all the selected 40 students on the first dental visit using Dentocult SM Strip Mutans test kit.

For the baseline status of $S$. mutans, the students were comfortably seated on the chair and unstimulated mid-morning salivary samples were collected. The bacitracin disks provided in the Dentocult SM Strip Mutans test kit were placed in the selective culture broth about 15 minutes before sampling (Fig. 1A). Instructions were given to the patients to swallow any excess saliva and then the rough surface of the round tipped strip was pressed against the saliva remaining on the tongue (Fig. 1B). The strips were then placed in the activated culture vials (Fig. 1C) followed by their incubation in an upright position at $37^{\circ} \mathrm{C}$ for 48 hours (Fig. 1D).

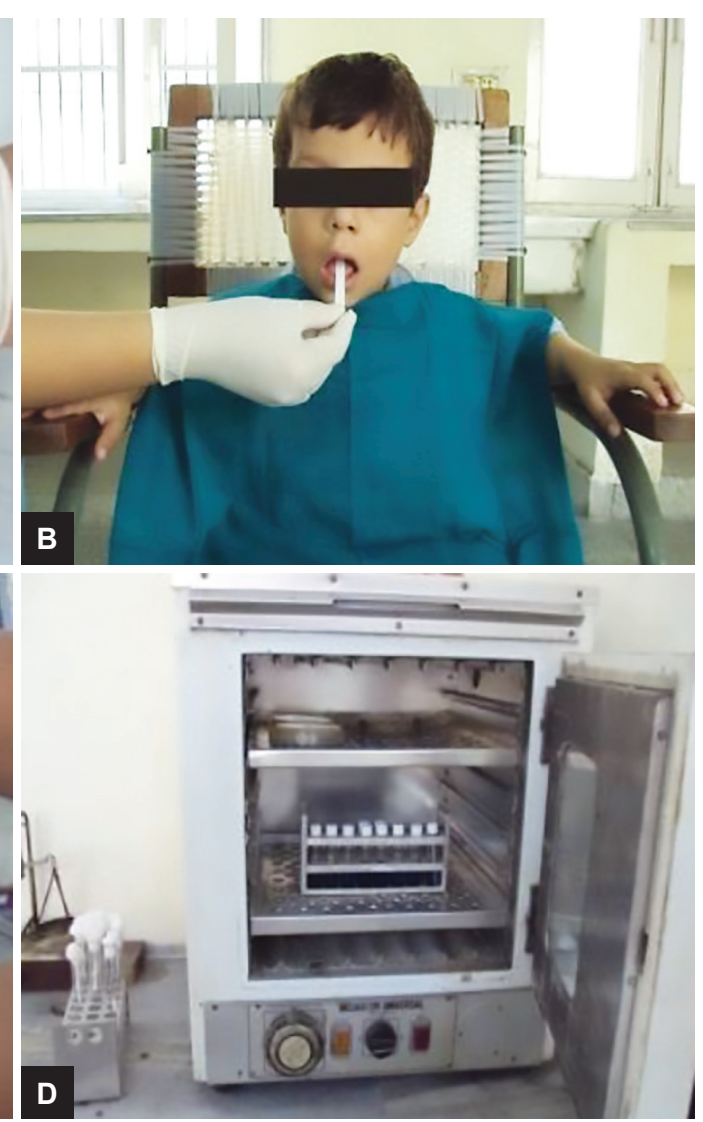

Figs 1A to D: The procedure of Dentocult SM Strip Mutans test. (A) Bacitracin disks in the culture vials. (B) Rough-tipped strip pressed against patients tongue. (C) Strip placed in activated culture vial. (D) Vials incubated at $37^{\circ} \mathrm{C}$ for 48 hour 


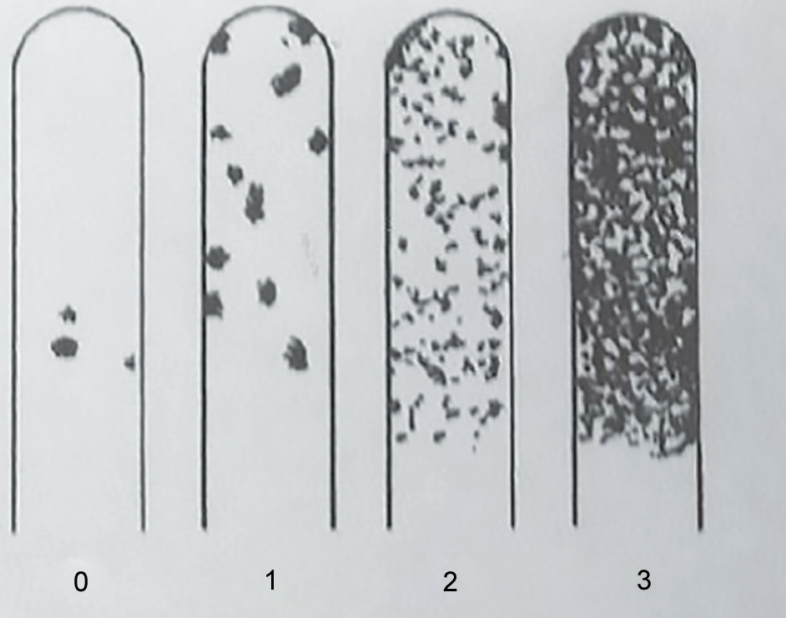

Fig. 2: Model chart. Class $0:<10,000 \mathrm{CFU} / \mathrm{mL}$; class $1:<100,000$ $\mathrm{CFU} / \mathrm{mL}$; class 2: 100,000-1,000,000 CFU/mL; class 3: $>100,000$ $\mathrm{CFU} / \mathrm{mL}$; CFU: Colony-forming unit

After incubation, the presence of mutans streptococci was evidenced by dark blue to light blue raised colonies on the rough surface of the strip. Colonies suspended in the selective culture broth were excluded from evaluation. The pretreatment levels of $S$. mutans were then evaluated by comparing the colony density against a chart provided by the manufacturer (Fig. 2).

Inspection of the growth was done sideways against light or with a magnifying glass to look for raised colonies.

Following the assessment of the initial S. mutans counts, the school students were randomly divided into four equal groups and were provided with a caries preventive regimen for 2 weeks (Table 1 ).

After 2 weeks, reduction, if any, in the S. mutans counts was assessed using Dentocult SM Strip Mutans test. The strips were then placed with the smooth surfaces clipped and attached to the cap in the selective culture vial that were prelabeled with the names of the children. After the collection of samples in the respective vials, the names

Table 1: Distribution of samples and their preventive regimes

\begin{tabular}{|c|c|c|c|}
\hline $\begin{array}{l}\text { Group } \\
\text { number }\end{array}$ & $\begin{array}{l}\text { Caries } \\
\text { preventive } \\
\text { measure } \\
\end{array}$ & $\begin{array}{l}\text { Regimen of the } \\
\text { preventive measure } \\
\text { (for } 2 \text { weeks) }\end{array}$ & $\begin{array}{l}\text { Number of } \\
\text { samples }\end{array}$ \\
\hline Group I & $\begin{array}{l}\text { Probiotic milk } \\
\text { (Yakult) }\end{array}$ & $\begin{array}{l}\text { Daily regimen of } 65 \mathrm{~mL} \\
\text { bottle of Probiotic milk } \\
\left(\text { Yakult }^{\circledR}\right)\end{array}$ & 10 \\
\hline Group II & $\begin{array}{l}\text { Chlorhexidine } \\
\text { mouthwash } \\
\left(\text { Hexidine }{ }^{\circledR}\right)\end{array}$ & $\begin{array}{l}\text { Daily regimen of } \\
\text { chlorhexidine mouthwash } \\
\text { (Hexidine }^{\circledR} \text { ) two times a } \\
\text { day }\end{array}$ & 10 \\
\hline Group III & $\begin{array}{l}\text { Dentifrice } \\
\text { (Babool) }\end{array}$ & $\begin{array}{l}\text { Brushing twice daily } \\
\text { with a nonfluoridated } \\
\text { toothpaste (Babool) }\end{array}$ & 10 \\
\hline Group IV & $\begin{array}{l}\text { Fluoride } \\
\text { varnish (Fluor } \\
\text { Protector) }\end{array}$ & $\begin{array}{l}\text { Fluoride varnish (Fluor } \\
\text { Protector) was applied on } \\
\text { the initial visit }\end{array}$ & 10 \\
\hline
\end{tabular}

were blocked by a different person and a new code was given to each vial. The evaluator was completely blind with this coding procedure. The coded culture vials were incubated at $37^{\circ} \mathrm{C}$ for 48 hours. After 48 hours, the posttreatment $S$. mutans counts of all the subjects were available to the interpreter for evaluation of results. After the results were evaluated, the vials were decoded and the results were tabulated.

The pretreatment and posttreatment scores of each subject in all the four groups were compared for the evaluation of $S$. mutans counts after 2 weeks' intervention of all the four caries preventive measures.

\section{RESULTS}

Table 2 (Graph 1) shows the mean values of overall reduction in $S$. mutans counts after 2 weeks of exposure to respective caries preventive measures. Out of the four preventive measures, the mean difference for the dentifrice group was observed to be minimum $(0.700 \pm 0.6749)$ followed by probiotic $(1.200 \pm 0.6325)$ and chlorhexidine $(1.500 \pm 0.5270)$. Maximum reduction was observed in subjects in whom varnish was used as the preventive measure $(2.700 \pm 0.4830)$.

Table 3 shows one-way analysis of variance and Kruskal-Wallis test for the reduction in S. mutans counts was done using various preventive regimes, and highly

Table 2: Difference in $S$ mutans counts following 2 weeks of different caries preventive measures

\begin{tabular}{lllll}
\hline Caries preventive measure & $n$ & Mean & $S D$ & $S E$ \\
\hline Probiotic milk (Group I) & 10 & 1.200 & 0.6325 & 0.200 \\
Chlorhexidine (Group II) & 10 & 1.500 & 0.5270 & 0.166 \\
Dentifrice (Group III) & 10 & 0.700 & 0.6749 & 0.213 \\
Varnish (Group IV) & 10 & 2.700 & 0.4830 & 0.152 \\
\hline
\end{tabular}

SD: Standard deviation; SE: Standard error

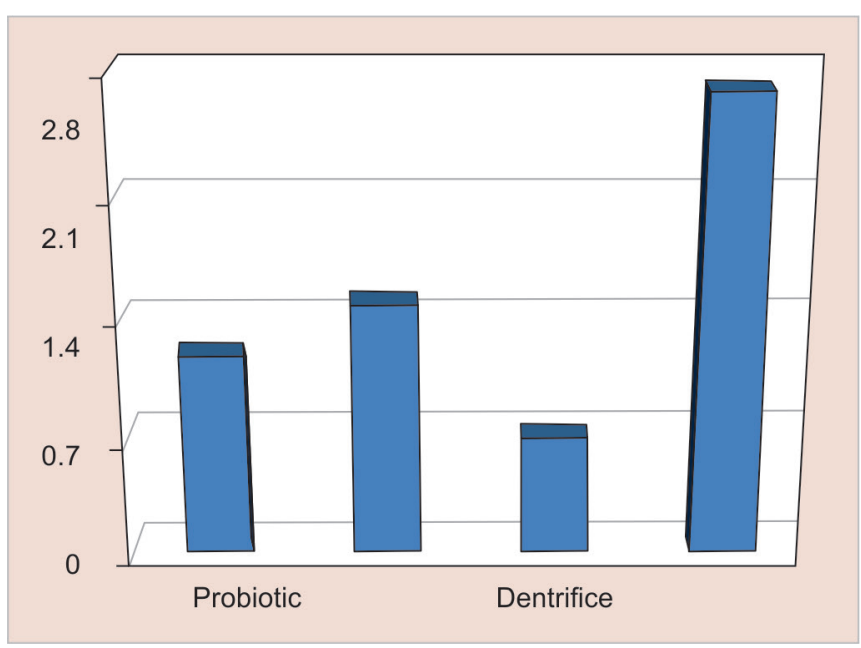

Graph 1: Overall reduction in S. mutans counts after 2 weeks of preventive regimes 
A Comparative Evaluation of Efficacy of Streptococcus mutans Counts in Saliva

Table 3: Analysis of variance (Kruskal-Wallis test) for efficacy of various caries preventive measures

\begin{tabular}{lllllll}
\hline $\begin{array}{l}\text { Preventive } \\
\text { measure }\end{array}$ & $n$ & Rank & Chi-square & $d f$ & $p$-value & Inference \\
\hline $\begin{array}{l}\text { Probiotic milk } \\
\text { (Group I) }\end{array}$ & 10 & 16.65 & 24.101 & 3 & 0 & HS \\
$\begin{array}{l}\text { Chlorhexidine } \\
\text { (Group II) }\end{array}$ & 10 & 20.50 & & & & \\
$\begin{array}{l}\text { Dentifrice } \\
\text { (Group III) }\end{array}$ & 10 & 10.70 & & & & \\
$\begin{array}{l}\text { Varnish } \\
\text { (Group IV) }\end{array}$ & 10 & 34.15 & & & & \\
\hline
\end{tabular}

S: Significant at $p<0.05$; NS: Not significant when $p>0.05$, HS: Highly significant when $p<0.01$, df: degree of freedom

significant differences $(\mathrm{p}<0.05)$ on various inter- and intragroup comparisons were observed.

Table 4 depicts nonsignificant results when group I (probiotic milk) was compared with group II (0.282) and group III (0.102) where Mann-Whitney test was used for intergroup comparisons. All other comparisons showed highly significant results. Highly significant results were observed when group IV was compared with group I (0.000), group III (0.000), and group II (0.001). Similarly, intergroup comparison of groups II and III also showed results of high significance (0.013).

\section{DISCUSSION}

In the present clinical study, for the purpose of evaluating the reduction in the $S$. mutans counts in respective groups for various intergroup comparisons, the mean reduction scores were calculated for all the four groups. The mean reduction in S. mutans counts was significant in all the four groups in our study. This indicated that all preventive measures used in our study had the potential to reduce $S$. mutans counts.

In the present study, the probiotic group showed significant reduction in S. mutans counts. The L. casie Shirota strain in the probiotic (Yakult) might have replaced the normal commensals in the oral biofilm that might have contributed to significant reduction in the $S$. mutans scores. These results were in accordance with a study by Hor et $\mathrm{al}^{5}{ }^{5}$ where a decreased mutans streptococci count was observed following a 2-week consumption of Yakult, although the decrease was found to be nonsignificant. However, Hor et $\mathrm{al}^{5}$ conducted their study in adults with the age group of 21 to 40 years, while the present study was done on children. Therefore, the difference in oral ecology of child and adult might have contributed to a nonsignificant reduction in the previous study.

A significant mean reduction of $S$. mutans scores was also observed with chlorhexidine mouthwash.
Table 4: Intergroup comparison of various caries preventive measures after 2 weeks using Mann-Whitney $U$ test

\begin{tabular}{llll}
\hline Intergroup & Mann-Whitney & & \\
comparison & U test & $p$-value & Inference \\
\hline Group I vs II & -1.076 & 0.282 & $\mathrm{NS}$ \\
Group I vs III & -1.636 & 0.102 & $\mathrm{NS}$ \\
Group I vs IV & -3.615 & 0.000 & $\mathrm{HS}$ \\
Group II vs III & -2.471 & 0.013 & $\mathrm{HS}$ \\
Group II vs IV & -3.425 & 0.001 & $\mathrm{HS}$ \\
Group III vs IV & -3.806 & 0.000 & $\mathrm{HS}$ \\
\hline
\end{tabular}

S: Significant at $p<0.05$; NS: Not significant, when $p>0.05$; HS: Highly significant when $p<0.01$

In the present study, $0.2 \%$ chlorhexidine mouthwash had exhibited a broad spectrum activity against $S$. mutans by preventing their colonization and reducing their number in the saliva. These results were similar to a study by Sari and Birinci, ${ }^{11}$ in which it was reported that patients using $0.2 \%$ chlorhexidine gluconate mouthrinse after toothbrushing every day once in the morning after breakfast and once in the evening before bedtime showed a significant decrease in $S$. mutans levels. These findings confirm those of Beyth et $\mathrm{al}^{12}$ in which chlorhexidine varnish was used.

Although significant, least mean reduction in $S$. mutans counts as compared with all the other three groups was observed in group III (dentifrice).

Toothbrushing is probably the most commonly performed oral hygiene practice in the world. The major purpose of this procedure is to lower the organisms in dental plaque that might be responsible for oral diseases / conditions including dental caries, periodontal diseases, and halitosis. ${ }^{13}$ This mechanical cleansing effect might be responsible for the reduction in the S. mutans counts following toothbrushing regimen in the present study. Also, it could be due to "Hawthorne effect"14 or a positive change in the behavior of subject as a result of special attention and status received from participation in an investigation.

Similar findings have been reported by Seow et $\mathrm{a}^{15}$ in which a single dental health education session and toothbrushing instruction to mothers resulted in approximately a $25 \%$ reduction in mutans streptococci infection in young children from a relatively high socioeconomic status.

The minimum reduction in S. mutans following toothbrushing in the present study could probably be because in this age group, there is decreased development of motor skills, difficulty in cleaning the teeth during the mixed dentition period leading to inadequate plaque removal from the caries-prone sites and also, according to Svanberg, ${ }^{16}$ sometimes toothbrushes are shown to be heavily infected by S. mutans, which may lead to the spread of these and other organisms from one site to another. 
The maximum mean reduction in $S$. mutans counts was observed in group IV where varnish was used as a preventive measure $(2.700 \pm 0.4830)$.

The high mean reduction in the $S$. mutans counts with the use of Fluor Protector varnish has been supported by a large number of studies conducted. ${ }^{17,18}$

The reduction of bacterial counts following the use of Fluor Protector varnish could be due to increase in the depth of fluoride penetration in enamel and root surfaces and enhanced retention of surface fluoride $\mathrm{e}^{19}$ and increased contact time between fluoride and enamel. ${ }^{20}$ The varnish also exhibits antibacterial effect by fluoride leached out and taken up by the tooth to inhibit the bacterial growth or direct entry of fluoride into the bacterial cell and inhibition of various cellular processes. ${ }^{4}$

The results of the present study are in accordance with the study conducted by Jeevarathan et al, ${ }^{4}$ in which statistically significant reduction $(p=0.000)$ in $S$. mutans counts was observed in plaque samples in 24 hours following the application of Fluor Protector varnish. Munshi et $\mathrm{al}^{18}$ evaluated the demineralizing inhibitory and antibacterial effects of Fluor Protector in an in vitro study and found that it had highest demineralizing inhibitory effect and the lowest antibacterial effect when compared with Bifluoride-12 and Fluoritop SR, which was due to a greater uptake of fluoride by enamel in the tooth sections treated by Fluor Protector in spite of its lower fluoride content. $^{21}$

Nonsignificant results were observed when group I (probiotic) was compared with group II (chlorhexidine). The nonsignificant difference among the groups might be due to the fact that both of them have a similar potential of "washing off" the cariogenic bacteria, that is, probiotic replaces the normal habitat in the oral biofilm and chlorhexidine, being bacteriostatic, prevents bacterial colonization on the tooth surface. Therefore, almost similar effects might have resulted in a nonsignificant difference between the two when intergroup comparisons were made. However, the mean reduction of both the groups showed highly significant results.

Highly significant results were obtained when Fluor Protector varnish was compared with probiotics. The greater reduction of Fluor Protector as compared with probiotic could be attributed to multiple effects exhibited by the varnish in S. mutans reduction and caries inhibition as compared with probiotics. Probiotics act by a single mechanism of displacing off the pathogenic bacteria from the biofilm by competitive inhibition, whereas Fluor Protector varnish may increase the depth of fluoride penetration in enamel and root surfaces, and enhances retention of surface fluoride, ${ }^{19}$ increases the contact time between fluoride and enamel, ${ }^{20}$ and exhibits its antibacterial effect by fluoride being leached out and taken up by the tooth to inhibit the bacterial growth or direct entry of fluoride into the bacterial cell and inhibition of various cellular processes. ${ }^{4}$ Also, highly significant results were observed in the present study when dentifrices were compared with chlorhexidine mouthwash and Fluor Protector varnishes.

The decreased reduction of dentifrice group as compared with the chlorhexidine and varnish in the present study could be attributed to the fact that toothbrushing is not always carried out thoroughly, does not remove plaque from some of the caries-prone sites and is shown sometimes to be heavily infected with $S$. mutans. ${ }^{16}$ The reduction observed in toothbrushing in the present study would only have been due to the "Hawthorne effect" or participation effect, which would have influenced the oral hygiene maintenance of the subjects.

However, when intergroup comparisons were made between Fluor Protector group and chlorhexidine group, there was a greater reduction with the Fluor Protector group as compared with the chlorhexidine group.

The decreased reduction following chlorhexidine mouthwash as compared with the varnish appears to be related primarily to incomplete eradication of mutans streptococci following the chlorhexidine mouthwash regimen, rather than reinoculation with the pathogen. ${ }^{21}$ Also, not all people harboring high mutans streptococci levels, however, respond optimally to hexidine treatment. Once the chlorhexidine treatment ceases, how quickly people return to pretreatment $S$. mutans levels varies considerably from subject to subject. ${ }^{22}$ Therefore, subjectto-subject variation and incomplete eradication following chlorhexidine regimen would have contributed to $S$. mutans reduction as compared with Fluor Protector varnish.

\section{CONCLUSION}

All the four caries preventive measures were effective in significantly reducing the $S$. mutans counts in saliva. Although there was a reduction in S. mutans scores among all the four groups, highest reduction was observed following the use of Fluor Protector varnish, and brushing with a nonfluoridated dentifrice showed least reduction as compared with the other caries preventive measures. Based on the results of the present study, the efficacy of various caries preventive measures can be graded as follows:

Fluor Protector $>$ Chlorhexidine mouthwash $>$ Probiotic (Yakult)> Brushing with a nonfluoridated dentifrice

\section{REFERENCES}

1. Bowen WH, Birkhed D. Dental caries: dietary and microbiology factors. In: Granath L, McHugh WD, editors. Systemized prevention of oral disease: theory and practice. Boca Raton (FL): CRC Press, Inc.; 1986. pp. 19-41. 
2. Pai V. Effect of single use toothbrush on plaque microflora. Indian J Dent Res 2009 Oct-Dec;20(4):404-406.

3. Emilson CG. Potential efficacy of chlorhexidine against mutans streptococci and human dental caries. J Dent Res 1994 Mar;73(3):682-691.

4. Jeevarathan J, Deepti A, Muthu MS, Rathana Prabhu V, Chamundeeshwari GS. Effect of fluoride varnish on Streptococcus mutans counts in plaque of caries free children using Dentocult SM Strip Mutans test: a randomized controlled triple blind study. J Indian Soc Pedod Prev Dent 2007 OctDec;25(4):157-163.

5. Hor GS, Meina T, Yin JF, Buiharto IP. Potential cariostatic effects of Yakult. Undergraduate Research Opportunities Programme 2007.

6. Krasse B. Caries risk. A practical guide for assessment and control. Chicago: Quintessence; 1985. p. 91.

7. Thaweboon B, Thaweboon S, Sopavanit C, Kasetsuwan R. A modified dip-slide test for microbiological risk in caries assessment. Southeast Asian J Trop Med Public Health 2006 Mar;37(2):400-404.

8. Alaluusua S, Savolainen J, Tuompo H, Gronroos L. Slidescoring method for estimation of Streptococcus mutans. Scand J Dent Res 1984 Apr;92(2):127-133.

9. Jensen B, Bratthall D. A new method for the estimation of mutans streptococci in human saliva. J Dent Res 1989 Mar;68(3):468-471.

10. Shi S, Liang Q, Hayashi Y, Yakushiji M, Machida Y. The relationship between caries activity and the status of dental caries-application of the Dentocult SM method. Chinese J Dent Res 1998 Dec;1(3):52-55.

11. Sari E, Birinci I. Microbiological evaluation of $0.2 \%$ chlorhexidine gluconate mouth rinse in orthodontic patients. Angle Orthod 2007 Sep;77(5):881-884.
12. Beyth N, Redlich M, Harari D, Freidman M, Steinberg D. Effect of sustained release chlorhexidine varnish on Streptococcus mutans and Actinomyces viscosus in orthodontic patients. Am J Orthod Dentofacial Orthop 2003 Mar;123(3):345-348.

13. Haffajee AD, Smith C, Torresyap G, Thompson M, Guerrero D, Socransky SS. Efficacy of manual and powered toothbrushes (II). Effect on microbiological parameters. J Clin Periodontol 2001 Oct;28(10):947-954.

14. Robertson PB, Armitage GA, Buchanan SA, Targgat EV. The design of trials to test the efficacy of plaque control agents for periodontal diseases in humans. J Dent Res 1989;68:1667-1671.

15. Seow WK, Cheng E, Wan V. Effect of oral health and toothbrushing on mutans streptococci infection in young children. Pediatr Dent 2003 May-Jun; 25(3):223-228.

16. Svanberg M. Contamination of toothbrush and toothpaste by Streptococcus mutans. Scand J Dent Res 1978 Sep;86(5):412-414.

17. Larsson KS, Modeer T, Twetman S. Fluoride concentration in plaque in adolescents after topical application of different fluoride varnishes. Clin Oral Investig 2000 Mar;4(1):31-34.

18. Munshi AK, Reddy NN, Shetty V. A comparative evaluation of three fluoride varnishes: an in-vitro study. J Indian Soc Pedod Prev Dent 2001 Sep;19(3):92-102.

19. Koritzer RT, Levy JS. Enhanced fluoride penetration and retention in enamel. Caries Res 1979;13(5):259.

20. Azarpazhooh A, Main PA. Fluoride varnish in the prevention of dental caries in children and adolescents: a systemic review. Tex Dent J 2008 Apr;125(4):318-337.

21. Kozai K, Wang DS, Sandham HJ, Phillips HI. Changes in strains of mutans streptococci induced by treatment with chlorhexidine varnish. J Dent Res 1991 Sep;70(9):1252-1257.

22. Maltz M, Zickert I, Krasse B. Effects of intensive treatment with chlorhexidine on number of Streptococcus mutans in saliva. Scand J Dent Res 1981 Dec;89(6):445-449. 